\title{
Fuzzy failure modes and effects analysis by using fuzzy Vikor and Data Envelopment Analysis-based fuzzy AHP
}

\author{
Aman Ullah Baloch*, Hossin Mohammadian \\ Mazandaran University of Science and Technology, Babol, Iran
}

\section{A R T I CLE INF O}

\section{Article history:}

Received 7 June 2016

Received in revised form

15 August 2016

Accepted 15 August 2016

\section{Keywords:}

FMEA

Vikor

DEA

AHP

Fuzzy method

\begin{abstract}
A B S T R A C T
In the Failure mode and effects analysis and its classical effects, the classical priorities are determined by means of risk priority number and risk factors multiplication. However, exact risk priorities are criticized by many researchers for its imperfections and disadvantages so that many studies done on Failure mode and effects analysis and its effects to dominate the issues. In this paper, linguistic variables are used that later on by trilingual fuzzy numbers are used to assess the weighs and ranks of risk factors. To determine the weighs of each risk factors, the fuzzy hierarchical analysis method and ranking with selection of the most important impairment manner and fuzzy Vikor method, Data Envelopment Analysis are used. The suggested model applies the assessment and potential manners of ranking in the production of width strength set of the radiator of Samand car in the car company of Iran.
\end{abstract}

(C) 2016 The Authors. Published by IASE. This is an open access article under the CC BY-NC-ND license (http://creativecommons.org/licenses/by-nc-nd/4.0/).

\section{Introduction}

Failure mode and effects analysis is a systematic method to recognize and predict the problem occurrence manufacturing in production and procession. This method focuses on problem prohibition, high safety and customer satisfaction. Now FMEA is used extensively in many industries like plane, car manufacturing, nuclear industry, electronics, chemical, mechanical and medicine. FMEA is an engineer technique that is used in recognition and deletion of failures, problems, errors in design or process or services before delivering to the costumer, in this method, three risk factors; severity (S), occurrence (0), and detectability (D) are evaluated and a risk priority number (RPN) is obtained by multiplying these factors. In this method RPN is the risk priority number that shows the importance of mutual relation of impairment and possibility of occurrence. In this regard, professional compare of errors and the most important cause of the problem are determined. FMEA uses the multiplication of three factors to determine the risk. The minimum number of risk priority is 1 and the maximum is 1000 that is the norm of evaluation of

\footnotetext{
* Corresponding Author.

Email Address: Aman.baloch2007@gmail.com (A. Baloch) http://dx.doi.org/10.21833/ijaas.2016.08.005

2313-626X/C) 2016 The Authors. Published by IASE.

This is an open access article under the CC BY-NC-ND license (http://creativecommons.org/licenses/by-nc-nd/4.0/)
}

risk impairment and the higher amount of it means the higher risk. The main issue in FMEA is the different compounds of occurrence, detection and severity that are gained through multiplication. For the different impairment manners the similar risk priority number is made so that may differ, since the importance of three factors is not equal. This study uses FMEA, VIKOR, DEA to fuzzy environment to determine the impairments and ranking in potential manners of width strength set of radiator in Samand car in Iran Company.

\section{Background}

In the fuzzy FMEA literature, the studies have mostly concerned with the fuzzy rule-based approach by using if-then rules (Bowles and Pelaez, 1995; Chin et al., 2008; Guimares and Lapa, 2004, 2007; Pillay and Wang, 2003; Sharma et al., 2005; Meng Tay and Peng Lim, 2006; Xu et al., 2002). After the assignments of the linguistic terms to the factors, if-then rules were generated taking the linguistic variables as inputs to evaluate the risks. The outputs of the fuzzy inference system were variously named as risk (Chin et al., 2008; Guimares and Lapa, 2004), the critically failure mode (Xu et al., 2002), priority for attention (Pillay and Wang, 2003), and fuzzy RPN (Sharma et al., 2005; Xu et al., 2002) in the fuzzy FMEA studies which consider the fuzzy rule-based approach.

There are many studies on FMEA to decrease the imperfections. Wang et al. (2009) introduce three 
factors of severity, detection and occurrence. These factors are scaled as 1-10. Braglia (2000) criticize that the failure modes characterized by the fuzzy ifthen rules could not be prioritized or ranked and there is no way to incorporate the relative importance of risk factors into the fuzzy inference system by using fuzzy if-then rules. Thus, they make a anew phase method in which the risk priority number as a geometrical means is used and measured by alpha level sets and linear models.

Wang et al. (2007) make risk assessment in FMEA by geometrical mean weigh. Make a support system to decide on fuzzy method to decrease the classic limitations. Puri and Yadav (2015) says that intuition fuzzy set is the extension of fuzzy series when data are not enough to introduce it. The models of FMEA, DEA are to assess the benefits of fuzzy in limited decision making on input and output fuzzy. Of course, in reality input and output may have intuition nature. AlKhathlan and Malik (2010) in are arabian banks effective? says that Saudi Arabia has a bank-base financial system compared with other countries of the region. He uses DEA, CCR, BCR and annual data of 2003-2008 to assess the beneficiary of Arabian banks. The results show that these banks are beneficial in financial resources management. Lai and Wei (2007) in Performance assessment by the model of data coverage says that financial issues are in search of a way to make a relation between production and efficiency to control the variations like sale amount, factory size, staffs number etc. Efficiency norms show that whether the model is beneficial or not. In this article, a process based on the DEA is used to rank the relative importance of performance. Amado et al. (2012) on synchronize of data coverage analysis states that this article aims at decision making units to represent a conceptual framework. Score card method is linked to DEA and this linkage results in 4 assessment aspects which include: financial, costumers, internal processes and learning and growth. The benefit of this model is tested in a multinational company.

However, determination of risk factors is not easy, as different decision makings may have different judgment or priorities. Wang and Pillay (2003) focused on three actors, while Braglia et al. (2003) on failure cause and high severity.

AHP, VIKOR, DEA are Fuzzy failure modes and effects that are focused here to increase efficiency. They are to be explained later on.

\section{Materials and methods}

Chang in 1992 represented a simple method for Fuzzy failure modes and effects process in fuzzy environment. It is a mean of other expert opinions and normalizes method by trilingual fuzzy numbers. The steps are in this way After the ranking of items based on the phase VIKOR, the opinions of the experts were de-phased and applied with GAMS software that is explained in the second chapter. The output results of risk priority of GAMS software with analysis technique and its effects are (Table 1):

Step 1: hierarchical tree design

Step 2: couple compared matrix: $\widetilde{T_{l j}}=\left(a_{i j}, b_{i j}, C_{i j}\right)$

Step 3: measure mean of opinions via matrix

$$
\tilde{A}=\left[\begin{array}{ccc}
(1,1,1) & \tilde{a}_{12} & \tilde{a}_{1 n} \\
\tilde{a}_{21} & (1,1,1) & \tilde{a}_{2 n} \\
\vdots & \vdots & \vdots \\
\tilde{a}_{n 1} & \tilde{a}_{n 2} & (1,1,1)
\end{array}\right]
$$

Table 1: Fuzzy judgment matrix

\begin{tabular}{|c|c|c|c|}
\hline performance & \multicolumn{2}{|c|}{ Potential impairments } & performance \\
\hline FM1 & Incorrect montage and bad conditions & FM7 & Bad installment of radiator particle \\
\hline FM2 & $\begin{array}{c}\text { In depth of boiling point test destroyed or } \\
\text { nuggets and hammer - line PSW1 (Welding } \\
\text { name)PSW2 }\end{array}$ & FM8 & $\begin{array}{c}\text { Linkage of boil point in demolition test of } \\
\text { PSW3 }\end{array}$ \\
\hline FM3 & $\begin{array}{c}\text { linkage of boil point in in hammer or nugget } \\
\text { PSW1, PSW2 }\end{array}$ & FM9 & P1 low core diameter in \\
\hline FM4 & $\begin{array}{c}\text { linkage of boil point in hammer or nugget } \\
\text { PSW1, PSW2 }\end{array}$ & FM10 & $\begin{array}{c}\text { linkage of boil points in demolition test of } \\
\text { PSW1,PSW2 }\end{array}$ \\
\hline FM5 & $\begin{array}{c}\text { low core diameter or incorrect particle in P1 } \\
\text {,P6 }\end{array}$ & FM11 & $\begin{array}{c}\text { low core diameter of demolition test of } \\
\text { hammer and nugget in PSW1,PSW2 }\end{array}$ \\
\hline FM6 & Incorrect installment of radiator particles & FM12 & $\begin{array}{c}\text { linkage of boil points in demolition test of } \\
\text { hammer and nugget of PSW1 AND PSW2 }\end{array}$ \\
\hline
\end{tabular}

$$
\begin{aligned}
& \tilde{A}=\left[\begin{array}{ccc}
(1,1,1) & \left\{\begin{array}{c}
\tilde{a} 121 \\
\tilde{a} 122 \\
\tilde{a} 12 p_{12}
\end{array}\right\} & \left\{\begin{array}{c}
\tilde{a} 1 n 1 \\
\tilde{a} 1 n 2 \\
\tilde{a} 1 n p_{1 n}
\end{array}\right\} \\
\left.\begin{array}{c}
\tilde{a} 211 \\
\tilde{a} 212 \\
\tilde{a} 21 p_{21}
\end{array}\right\} & (1,1,1) \\
\left\{\begin{array}{c}
\tilde{a} 2 n 1 \\
\tilde{a} \quad 2 n 11 \\
\tilde{a} 2 n 12 \\
\tilde{a} 2 n p_{2 n}
\end{array}\right\} & \left\{\begin{array}{c}
\tilde{a} n 21 \\
\tilde{a} n 22 \\
\tilde{a} n 1 p_{n 1}
\end{array}\right\} & (1,1,1)
\end{array}\right] \\
& \tilde{a}_{\mathrm{ij}}=\frac{\sum_{k=1}^{p_{i j}} a_{i j k}}{P_{i j}} \quad \mathrm{i} j=1,2, \ldots, n
\end{aligned}
$$

Step 4: accounting of line sets:

$$
\tilde{s}_{j}=\sum_{j=1}^{n} \widetilde{a \imath \jmath} \quad i j=1,2, \cdots, n
$$

Step 5: normalizing the line sets:

$$
\begin{aligned}
& \widetilde{M}_{i}=\tilde{s}_{i} \otimes\left[\sum_{i=1}^{n} \widetilde{s_{l}}\right]^{-1} i=1,2, \cdots n \\
& \tilde{m}_{i}=\left(\frac{i_{j}}{\sum_{i=1}^{n} u_{j}}, \frac{m_{i}}{\sum_{i=1}^{n} m_{j}}, \frac{u_{i}}{\sum_{i=1}^{n} l_{j}}\right)
\end{aligned}
$$


Step 6: determination of bigger possibility: the maximum possibility is $\mathrm{d}(\mathrm{Ai})$ which is evaluated as

$$
v\left(m_{2}>m_{1}\right)=s u b_{y \geq x}\left[\min \left(\mu x_{1}(x), \mu_{x_{2}}(y)\right)\right]
$$

The relationships can be defined in this way as well:

$$
\begin{gathered}
V\left(\tilde{M_{2} \geq} M_{2}\right)=\mu(d)= \\
1, \\
0, \\
\frac{l_{2}-u_{2}}{\left(m_{2}-u_{2}\right)-\left(m_{1}-l_{1}\right)} \text { other wise, }
\end{gathered}
$$

wherein $\mathrm{d}$ is highest point of common region (Fig. 1).

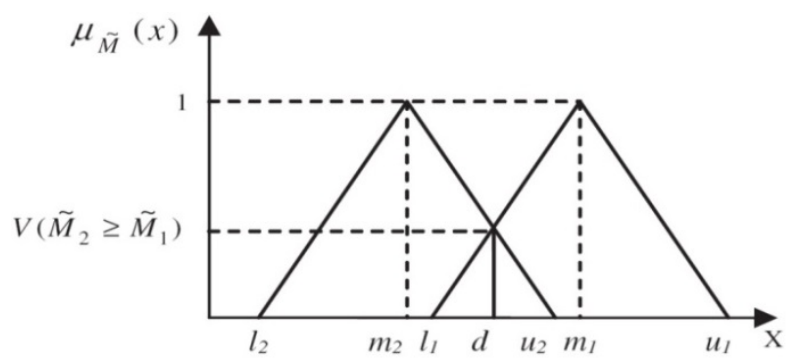

Fig. 1: The intersection between $\widetilde{M}_{1}$ and $\widetilde{M}_{2}$

V (M2 $\geq$ M1), V(M1 $\geq$ M2 are essential to compare $\mathrm{M}_{1}$ and $\mathrm{M}_{2}$. The bigger possibility is analyzed in this way):

$$
\begin{aligned}
& d^{\prime}(M)=V\left(M \geq M_{1}, M_{2}, \ldots, M_{k}\right)=V\left[\left(M \geq M_{1}\right)\left(M \geq M_{2}\right),\right. \\
& \left.\ldots,\left(M \geq M_{k}\right)\right]=\min V\left(M \geq M_{i}\right) i=1,2, \ldots, k
\end{aligned}
$$

Step 7: normalizing to make weight bidders:

$$
W=\left[\frac{d^{\prime}\left(A_{1}\right)}{\sum_{i=1}^{n} d^{\prime}\left(A_{i}\right)^{\prime}} \frac{d^{\prime}\left(A_{1}\right)}{\sum_{i=1}^{n} d^{\prime}\left(A_{i}\right)^{\prime}} \frac{d^{\prime}\left(A_{n}\right)}{\sum_{i=1}^{n} d^{\prime}\left(A_{n}\right)^{\prime}}\right]^{T}
$$

The above weights are non-fuzzy. Matrix weights are evaluated by repetition.

Step 8: weight compounds to make the final weights.

$$
\tilde{u}_{i}=\sum_{i=1}^{n} \widetilde{w}_{i} \tilde{r}_{i j} \quad \forall i
$$

\subsection{Vikor method}

In this method the worst item is used to ranking and finding of the best item and adaptability of items with the best one is classified. In this method, the items distance and importance of them with the best one is considered.

This method is one of the efficient methods that focus on the step by step process.

Step 1: $f_{i}^{-} f_{i}^{*}$

Based on the normal fuzzy matrix the best fuzzy amount and the worst fuzzy amount are evaluated: Step 2: accounting the $S \mathrm{j}, \mathrm{R} \mathrm{j}, \mathrm{Q} \mathrm{j}$

$$
\begin{aligned}
& f_{j}^{*}=\max _{x i j} ; f_{j}^{-}=\min _{x_{i j}} \\
& \tilde{s}_{i}=\sum_{j=1}^{k} \widetilde{W}_{j}\left(\tilde{f}_{j}^{*}-\tilde{x}_{i j}\right) /\left(\tilde{f}_{j}^{*}-\tilde{f}_{j}^{-}\right) \\
& \tilde{R}_{i}=\max j\left[\tilde{W}_{j}\left(\tilde{f}_{j}^{*}-\tilde{x}_{i j}\right) /\left(\tilde{f}_{j}^{*}-\tilde{f}_{j}^{-}\right)\right]
\end{aligned}
$$

When the above amounts are made, the norm of $\mathrm{Q}$ is used for all of the items:

$$
Q_{j}=V\left[\frac{\left(s_{j}-s^{-}\right)}{\left(s^{*}-s^{-}\right)}\right]+(1+V)\left[\frac{\left(R_{j}-R^{-}\right)}{\left(R^{*}-R^{-}\right)}\right]
$$

Wherein $S^{\wedge}(*)=\operatorname{maxj} \quad s j, \quad S^{\wedge}(-\quad)=\operatorname{minj} S j$, $\mathrm{R}^{\wedge}\left({ }^{*}\right)=\operatorname{maxjRj}, \mathrm{R}^{\wedge}(-)=\operatorname{minjRj} . \mathrm{Q}$ is the Vikor norm and $\mathrm{V}$ is the weight for strategy of the group that has the range of $0-10$.

Step 3: ranking of the items

For ranking the items, the $\mathrm{Q}, \mathrm{R}, \mathrm{S}$ should be ranked in descending manner.

A: the acceptable efficiency

$$
\mathrm{Q}\left(A_{2}\right)-\mathrm{Q}\left(A_{1}\right) \geq 1 /(n-1)
$$

Where in $A_{2}$ is best second item with the best item of $Q$ and the least amount of $n$.

B: acceptability in decision making

$A_{1}$ in $S$ or $R$ should have the best rank and it is in line with stable decision making so that $\mathrm{V}>0.5$ and the commonality is achieved when $\mathrm{V}<0.5$.

If the second condition is not achieved

If the fist condition is not achieved then $Q(A n)-Q$ $(\mathrm{An}-1 \geq 1 /(\mathrm{n}-1)$ is true.

\subsection{DEA method (without input or output)}

When there is $\mathrm{n}$ failure manner for prioritizing, each one is studied with risk factors of $\mathrm{m}$ :

Let rij $(i=1, \ldots, n ; j=1, \ldots, m)$ and $W$ is the weight of risk factor and the three factors are criticized mathematically. Failure risks with a mathematical form are defined differently as such:

$$
\begin{aligned}
& R_{i}=\sum_{j=1}^{m} w_{j} r_{i j}, i=1=, \ldots, n \\
& R_{i}=\prod_{j=1}^{m} r_{i j}^{w_{j}}, i=1, \ldots, n
\end{aligned}
$$

In the equation 10 , the risk of each failure manner is a set of weight risks, while in equation 9 it is the weight product of risk factor; to have a clear distinction. To have an easy distinction between two risks, in the equation 10 the added risk and equation risk of equation 11 is a multiply risk. DEA is classical for many zeroes for weights of input and output that results in high efficiency optimistically and low pessimistically. To prevent this, the relation of maximum weight to minimum is considered and maximum to minimum weight is in the range of 1-9 so that we can see:

$$
\begin{aligned}
& 1 \leq \frac{\max \left\{w_{1}, \cdots, w_{m}\right\}}{\min \left\{w_{1}, \cdots, w_{m}\right\}} \leq 9 \\
& \max \left\{\frac{w_{j}}{w k} \mid j \cdot k=1, \ldots, m: k \neq j\right\} \leq 9 \\
& w_{j}-9 w_{k} \leq 0, j, k=1, \ldots, m: k \neq j
\end{aligned}
$$


Regarding the defined DEA, now we can make FMEA models to measure the maximum and minimum risk of each failure mode.

$$
\begin{aligned}
& R_{0}^{\max }=\max \text { imize } R_{0} \\
& \text { subject to }\left\{\begin{array}{c}
R_{i} \leq 1, \quad i=1, \ldots, n, \\
W_{j}-9 w_{k} \leq 0, j, k=1, \ldots, m ; k \neq j
\end{array}\right\} \\
& R_{0}^{\min }=\min \text { imize } R_{0} \\
& \text { subject to }\left\{\begin{array}{c}
R_{i} \geq 1, \quad i=1, \ldots, n, \\
W_{j}-9 w_{k} \leq 0, j, k=1, \ldots, m ; k \neq j
\end{array}\right\}
\end{aligned}
$$

wherein $\mathrm{R}_{0}$ is the risk of failure mode under the study and total risk of each mode is the mean of maximum and minimum risks of failure mode.

$$
\bar{R}_{i}=\sqrt{R_{i}^{\max } \cdot R_{i}^{\min }}, i=1, \ldots, n
$$

This definition makes us calm in the range of failure mode risk. The higher geometric mean, the higher risk priority will be. $\mathrm{N}$ failure mode can be easily prioritized with geometric mean risks.

The models of 15 and 16 are added to the risks. The maximum and minimum risk models are made as well to the defined multiplied risks. But ranking and risks need logarithmic scales to be linear. The two models are:

$$
\ln R_{0}^{\max }=\max \text { imize } \ln R_{0}
$$

subject to $\left\{\begin{array}{c}\ln R_{i} \leq 1, \quad i=1, \ldots, n, \\ W_{j}-9 w_{k} \leq 0, j, k=1, \ldots, m ; k \neq j\end{array}\right\}$

$\ln R_{0}^{\min }=\min$ imize $\ln R_{0}$

subject to $\left\{\begin{array}{c}\ln R_{i} \geq 1, \quad i=1, \ldots, n, \\ W_{j}-9 w_{k} \leq 0, j, k=1, \ldots, m ; k \neq j\end{array}\right\}$

In this regard, geometric mean risk is defined as: Wherein EXP is function façade.

$\bar{R}_{i}=\sqrt{E X P\left(\ln R_{i}^{\text {max }}\right) \cdot E X P\left(\ln R_{i}^{\text {min }}\right)}, i=1, \ldots, n$

\section{Methodology}

The present study is research, descriptive and uses VIKOR, AHP, FMEA, DEA methods. The data of the study are collected by a team work of Iran Car Company every year with special cards anf the members of the team are some experts in research and improvement, quality control, product manager. The real data of the company is used and risk factors weights model is out of FAHP and the data are ranked via VIKOR and DEA.

\section{Results}

In this study, the suggested model in Iran Car

\begin{tabular}{|c|c|c|c|}
\hline performance & Potential impairments & performance & Potential impairments \\
\hline FM13 & $\begin{array}{l}\text { P1ow core diameter of demolition test of } \\
\text { hammer and nugget P6 }\end{array}$ & FM27 & $\begin{array}{l}\text { Linkage of boil point in hammer or nugget of } \\
\text { PSW3 }\end{array}$ \\
\hline FM14 & $\begin{array}{l}\text { P6 low core diameter of demolition test of } \\
\text { hammer and nugget PSW3 }\end{array}$ & FM28 & $\begin{array}{l}\text { Linkage of boil point in demolition test for } \\
\text { hammer or nugget of PSW3 }\end{array}$ \\
\hline FM15 & $\begin{array}{l}\text { Incorrect position of linear boil points } \\
\text { PSW1, PSW2 }\end{array}$ & FM29 & Outgrowth and flash \\
\hline FM16 & $\begin{array}{l}\text { Low core diameter in hammer and nugget } \\
\text { of PSW3 }\end{array}$ & FM30 & Burning or hole \\
\hline FM17 & $\begin{array}{l}\text { linkage of boil point in demolition test of } \\
\text { hammer and nugget PSW3 }\end{array}$ & FM31 & deformation \\
\hline FM18 & $\begin{array}{l}\text { linkage of boil point in demolition test of } \\
\text { hammer and nugget PSW3 }\end{array}$ & FM32 & Forget of boil points of PSW3 \\
\hline FM19 & $\begin{array}{l}\text { linkage of boil point in demolition test of } \\
\text { hammer and nugget PSW3 }\end{array}$ & FM33 & Incorrect positions of line boil points of PSW3 \\
\hline FM20 & forget of boil points of PSW1, PSW2 & FM34 & Final product dye \\
\hline FM21 & Incorrect installation of radiator particles & FM35 & Raw material deformation \\
\hline FM22 & Final product deformation & FM36 & Outgrowth and flash \\
\hline FM23 & Decrement of boil point & FM37 & Burning or hole \\
\hline FM24 & Low core diameter in PSW3 & FM38 & Raw particles dye \\
\hline FM25 & $\begin{array}{l}\text { Linkage of boil point in demolition test in } \\
\text { PSW3 }\end{array}$ & FM39 & $\begin{array}{l}\text { linkage of boil point in demolition test of } \\
\text { hammer and nugget PSW1, PSW2 }\end{array}$ \\
\hline FM26 & $\begin{array}{l}\text { Linkage of boil point in hammer or nugget } \\
\text { of the PSW3 }\end{array}$ & FM40 & $\begin{array}{c}\text { low core diameter of demolition test of hammer } \\
\text { and nugget P1, P6 }\end{array}$ \\
\hline
\end{tabular}
Company is used and primary interviews were with experts of quality control of the company. 40 potential impairment in production of Samand Radiator were reported (Table 2).

Table 2: Potential impairments in production of Samand radiator

After determination of impairments, the importance of risk factors was extracted by lingual variations and couple decision making matrix in the form of phase hierarchical method (Table 3).

For example, in the compare of risk factors, the response of three experts are relatively high, very high and very much.to extract the weights of risk factors with the method of phase hierarchical analysis, it is noteworthy that changing lingual variations to trilingual numbers the following table is used (Table 4).

Then, the experts analyzed ranking of 40 impairment modes with lingual variations (Table 5). 
Table 3: Matrix compare of couple risk factors based on lingual variations

\begin{tabular}{|c|c|c|c|}
\hline Detection & Occurrence & Severity & $\begin{array}{l}\text { Couple compare } \\
\text { matrix }\end{array}$ \\
\hline SS,SS,E & FS,VS,FS & E,E,E & severity \\
\hline SS,E,E & $\mathrm{E}, \mathrm{E}, \mathrm{E}$ & - & Occurrence \\
\hline $\mathrm{E}, \mathrm{E}, \mathrm{E}$ & & & detection \\
\hline
\end{tabular}

Table 4: Lingual words for variations ranking Fuzzy scores Linguistic words

\begin{tabular}{|c|c|}
\hline$(0,0,1)$ & Very low(VP) \\
\hline$(0,1,3)$ & Weak (P) \\
\hline$(1,3,5)$ & Little low (MP) \\
\hline$(3,5,7)$ & Average(F) \\
\hline$(5,7,9)$ & Little high (MG) \\
\hline$(7,9,10)$ & High (G) \\
\hline$(9,10,10)$ & Very high (VG) \\
\hline
\end{tabular}

Table 5: 40 impairment modes regarding three risk factors

\begin{tabular}{|c|c|c|c|c|c|c|c|c|c|c|}
\hline \multicolumn{3}{|c|}{ D } & \multicolumn{3}{|c|}{$\mathrm{S}$} & \multicolumn{3}{|c|}{0} & \multirow{2}{*}{\multicolumn{2}{|c|}{$\begin{array}{l}\text { Team decision making } \\
\text { matrix }\end{array}$}} \\
\hline $\begin{array}{c}\text { DM } \\
3\end{array}$ & DM2 & DM1 & DM3 & DM2 & DM1 & DM3 & DM2 & DM1 & & \\
\hline $\mathrm{F}$ & $\mathrm{F}$ & $\mathrm{G}$ & $\mathrm{G}$ & MG & G & $\mathrm{G}$ & MP & $\mathrm{F}$ & FM1 & \\
\hline MP & MP & $\mathrm{F}$ & MG & $\mathrm{F}$ & $\mathrm{MG}$ & MP & $\mathrm{F}$ & $\mathrm{F}$ & FM2 & \\
\hline $\mathrm{G}$ & MG & $\mathrm{G}$ & MG & $\mathrm{F}$ & MG & $\mathrm{F}$ & MP & MP & FM3 & \\
\hline $\mathrm{F}$ & $\mathrm{F}$ & $\mathrm{F}$ & MG & $\mathrm{G}$ & MG & GM & MG & $\mathrm{G}$ & FM4 & \\
\hline $\mathrm{F}$ & $\mathrm{G}$ & $\mathrm{MG}$ & $\mathrm{G}$ & VG & $\mathrm{G}$ & $\mathrm{F}$ & $\mathrm{F}$ & $\mathrm{F}$ & FM5 & \\
\hline MG & MG & MG & $\mathrm{F}$ & MG & MG & $\mathrm{F}$ & $\mathrm{F}$ & MG & FM6 & \\
\hline MG & MG & $\mathrm{G}$ & $\mathrm{MG}$ & $\mathrm{G}$ & $\mathrm{MG}$ & MP & $\mathrm{F}$ & MP & FM7 & \\
\hline $\mathrm{F}$ & MG & MG & MG & $\mathrm{F}$ & MG & $\mathrm{F}$ & $\mathrm{F}$ & MP & FM8 & \\
\hline $\mathrm{F}$ & MG & MG & MG & G & MG & $\mathrm{F}$ & MP & MP & FM9 & \\
\hline MG & $\mathrm{G}$ & MG & $\mathrm{G}$ & G & MG & MG & $\mathrm{F}$ & $\mathrm{F}$ & FM10 & \\
\hline $\mathrm{F}$ & $\mathrm{F}$ & MG & $\mathrm{MG}$ & $\mathrm{F}$ & MG & MG & $\mathrm{MG}$ & $\mathrm{G}$ & FM11 & \\
\hline MG & MG & MG & MG & $\mathrm{G}$ & MG & MG & MP & MP & FM12 & \\
\hline $\mathrm{MG}$ & MG & MG & MG & MG & $\mathrm{G}$ & MG & $\mathrm{F}$ & MP & FM13 & \\
\hline $\mathrm{MG}$ & $\mathrm{G}$ & $\mathrm{G}$ & $\mathrm{F}$ & MG & $\mathrm{F}$ & MG & $\mathrm{F}$ & MP & FM14 & \\
\hline VG & $\mathrm{G}$ & VG & MG & $\mathrm{F}$ & $\mathrm{MG}$ & VG & MP & $\mathrm{P}$ & FM15 & \\
\hline MP & MP & $\mathrm{F}$ & $\mathrm{F}$ & G & MG & MP & MP & $\mathrm{F}$ & FM16 & \\
\hline $\mathrm{G}$ & $\mathrm{F}$ & MG & G & $\mathrm{F}$ & MG & $\mathrm{G}$ & $\mathrm{P}$ & MP & FM17 & \\
\hline $\mathrm{MG}$ & G & MG & MG & $\mathrm{F}$ & MG & MG & $\mathrm{F}$ & $\mathrm{MG}$ & FM18 & \\
\hline $\mathrm{MG}$ & G & MG & $\mathrm{MG}$ & $\mathrm{G}$ & MG & MG & $\mathrm{F}$ & MP & FM19 & \\
\hline MG & $\mathrm{G}$ & VG & $\mathrm{F}$ & MG & MG & MG & MP & $\mathrm{P}$ & FM20 & Impairment \\
\hline MG & MG & $\mathrm{G}$ & $\mathrm{G}$ & $\mathrm{F}$ & MG & MG & $\mathrm{P}$ & MP & FM21 & modes \\
\hline MP & MG & MG & MG & VG & $\mathrm{G}$ & MP & MP & MP & FM22 & \\
\hline MG & MG & MG & MG & VG & G & MG & $\mathrm{P}$ & $\mathrm{P}$ & FM23 & \\
\hline $\mathrm{P}$ & MP & MP & $\mathrm{F}$ & $\mathrm{G}$ & MG & $\mathrm{P}$ & $\mathrm{F}$ & $\mathrm{F}$ & FM24 & \\
\hline MP & $\mathrm{F}$ & $\mathrm{F}$ & $\mathrm{F}$ & G & MG & MP & MG & $\mathrm{F}$ & FM25 & \\
\hline MG & MP & $\mathrm{F}$ & G & $\mathrm{F}$ & MG & MG & MP & $\mathrm{F}$ & FM26 & \\
\hline MG & MP & $\mathrm{F}$ & $\mathrm{F}$ & G & MG & MG & $\mathrm{F}$ & $\mathrm{F}$ & FM27 & \\
\hline MP & MG & $\mathrm{F}$ & G & G & MG & MP & $\mathrm{F}$ & MP & FM28 & \\
\hline MG & MG & $\mathrm{F}$ & MP & $\mathrm{F}$ & MP & MG & MG & $\mathrm{F}$ & FM29 & \\
\hline $\mathrm{F}$ & $\mathrm{F}$ & $\mathrm{F}$ & $\mathrm{F}$ & MG & $\mathrm{F}$ & $\mathrm{F}$ & MG & $\mathrm{F}$ & FM30 & \\
\hline G & MG & G & $\mathrm{P}$ & MP & $\mathrm{P}$ & G & MG & G & FM31 & \\
\hline $\mathrm{G}$ & MG & G & MG & $\mathrm{G}$ & MG & G & MP & $\mathrm{P}$ & FM32 & \\
\hline MG & MG & G & G & G & MG & $\mathrm{MG}$ & MP & $\mathrm{P}$ & FM33 & \\
\hline $\mathrm{G}$ & $\mathrm{F}$ & MG & G & $\mathrm{F}$ & MG & $\mathrm{G}$ & $\mathrm{P}$ & MP & FM34 & \\
\hline $\mathrm{F}$ & G & MG & $\mathrm{F}$ & $\mathrm{G}$ & MG & $\mathrm{F}$ & $\mathrm{F}$ & MP & FM35 & \\
\hline G & $\mathrm{F}$ & MG & MG & MP & $\mathrm{F}$ & G & MP & $\mathrm{F}$ & FM36 & \\
\hline $\mathrm{G}$ & $\mathrm{F}$ & MG & MG & MP & $\mathrm{F}$ & $\mathrm{G}$ & $\mathrm{P}$ & MP & FM37 & \\
\hline MG & $\mathrm{G}$ & MG & $\mathrm{F}$ & $\mathrm{MG}$ & $\mathrm{F}$ & MG & $\mathrm{F}$ & MP & FM38 & \\
\hline $\mathrm{G}$ & $\mathrm{G}$ & MG & MG & $\mathrm{G}$ & MG & $\mathrm{G}$ & $\mathrm{F}$ & MP & FM39 & \\
\hline $\mathrm{F}$ & $\mathrm{F}$ & MG & G & MG & $\mathrm{G}$ & $\mathrm{F}$ & $\mathrm{P}$ & $\mathrm{P}$ & FM40 & \\
\hline
\end{tabular}

Linguistic evaluation is shown in Table above and the following triangular fuzzy numbers are converted according to the table (Table 6).

Table 6: Lingual phrases of fuzzy score

\begin{tabular}{|c|c|}
\hline Fuzzy score & Linguistic terms \\
\hline$(2,5 / 2,3)$ & Absolutely strong (AS) \\
\hline$(3 / 2,2,5 / 2)$ & Very strong (VS) \\
\hline$(1,3 / 2,2)$ & Fairly strong (FS) \\
\hline$(1,1,3 / 2)$ & Slightly strong (SS) \\
\hline$(1,1,1)$ & Equal (E) \\
\hline$(2 / 3,1,1)$ & Slightly weak (SW) \\
\hline$(1 / 2,2 / 3,1)$ & Fairly weak (FW) \\
\hline$(2 / 5,1 / 2,2 / 3)$ & Very weak (VW) \\
\hline$(1 / 3,2 / 5,1 / 2)$ & Absolutely weak (AW) \\
\hline
\end{tabular}

The phase mean of experts opinions were gained through study of the norms and then VIKOR method was followed.

The parameter of $\mathrm{V}$ weight is the team desired maximum that can be in the range of 0 and 1 and in this study it is 0.5

The amounts of $Q, R, S$ were fixed:

$$
\operatorname{Crisp}(\widetilde{N})=\frac{2 m+l+r}{4}
$$

Then the real amounts for each one of impairment modes were gained through FAHP regarding the first step of VIKOR.

Then we arrange $\mathrm{Q}, \mathrm{R}, \mathrm{S}$ in descending order. 
After the ranking of items based on the phase VIKOR, the opinions of the experts were de-phased and applied with GAMS software that is explained in the second chapter. The output results of risk priority of GAMS software with analysis technique and its effects are in Table 7, 8 and 9.

Table 7: Values for certain failure modes

\begin{tabular}{|c|c|c|c|c|c|c|c|}
\hline & C1 & $\mathrm{C} 2$ & C3 & & C1 & C2 & C3 \\
\hline Type Criteria & Positive & Positive & Positive & Type Criteria & Positive & Positive & Positive \\
\hline $\mathrm{A} 1$ & $\begin{array}{l}(6.333,8.3 \\
33,9.667)\end{array}$ & $\begin{array}{c}(3.667,5.66 \\
7,7.333)\end{array}$ & $\begin{array}{c}(4.333,6.3 \\
33,8)\end{array}$ & A21 & $(5,7,8.667)$ & $(1.333,3,5)$ & $\begin{array}{l}(5.667,7.6 \\
67,9.333)\end{array}$ \\
\hline $\mathrm{A} 2$ & $\begin{array}{l}(4.333,6.3 \\
33,8.333)\end{array}$ & $\begin{array}{c}(2.333,4.33 \\
3,6.333)\end{array}$ & $\begin{array}{l}(1.667,3.6 \\
67,5.667)\end{array}$ & A22 & $\begin{array}{c}7,8.667,9 . \\
667)\end{array}$ & $\begin{array}{l}(0.667,2.3 \\
33,4.333)\end{array}$ & $\begin{array}{l}(3.667,5.6 \\
67,7.667)\end{array}$ \\
\hline A3 & $\begin{array}{l}4.333,6.3 \\
33,8.333)\end{array}$ & $\begin{array}{c}(1.667,3.66 \\
7,5.667)\end{array}$ & $\begin{array}{l}6.333,8.3 \\
33,9.667)\end{array}$ & A23 & $\begin{array}{c}(7,8.667,9 . \\
667)\end{array}$ & $(0,1,3)$ & $(5,7,9)$ \\
\hline $\mathrm{A} 4$ & $\begin{array}{l}(5.667,7.6 \\
67,9.333)\end{array}$ & $\begin{array}{c}(5.667,7.66 \\
7,9.333)\end{array}$ & $(3,5,7)$ & A24 & $(5,7,8.667)$ & $\begin{array}{l}(2.333,4.3 \\
33,6.333)\end{array}$ & $\begin{array}{l}(0.667,2.3 \\
33,4.333)\end{array}$ \\
\hline A5 & $\begin{array}{c}(7.667,9.3 \\
33,10)\end{array}$ & $(3,5,7)$ & $(5,7,8.667)$ & A25 & $(5,7,8.667)$ & $\begin{array}{l}(4.333,6.3 \\
33,8.333)\end{array}$ & $\begin{array}{l}(2.333,4.3 \\
33,6.333)\end{array}$ \\
\hline A6 & $\begin{array}{l}(4.333,6.3 \\
33,8.333)\end{array}$ & $\begin{array}{c}3.667,5.66 \\
7,7.667)\end{array}$ & $(5,7,9)$ & A26 & $(5,7,8.667)$ & $(3,5,7)$ & $(3,5,7)$ \\
\hline A7 & $\begin{array}{l}(5.667,7.6 \\
67,9.333)\end{array}$ & $\begin{array}{c}(1.667,3.66 \\
7,5.667)\end{array}$ & $\begin{array}{l}(5.667,7.6 \\
67,9.333)\end{array}$ & $\mathrm{A} 27$ & $(5,7,8.667)$ & $\begin{array}{l}(3.667,5.6 \\
67,7.667)\end{array}$ & $(3,5,7)$ \\
\hline A8 & $\begin{array}{l}4.333,6.3 \\
33,8.333)\end{array}$ & $\begin{array}{c}(2.333,4.33 \\
3,6.333)\end{array}$ & $\begin{array}{l}(4.333,6.3 \\
33,8.333)\end{array}$ & A28 & $\begin{array}{l}(6.333,8.3 \\
33,9.667)\end{array}$ & $\begin{array}{l}(1.667,3.6 \\
67,5.667)\end{array}$ & $(3,5,7)$ \\
\hline A9 & $\begin{array}{l}(5.667,7.6 \\
67,9.333)\end{array}$ & $\begin{array}{c}(1.667,3.66 \\
7,5.667)\end{array}$ & $\begin{array}{l}(4.333,6.3 \\
33,8.333)\end{array}$ & A29 & $\begin{array}{l}(1.667,3.6 \\
67,5.667)\end{array}$ & $\begin{array}{l}(3.667,5.6 \\
67,7.667)\end{array}$ & $\begin{array}{l}(4.333,6.3 \\
33,8.333)\end{array}$ \\
\hline $\mathrm{A} 10$ & $\begin{array}{l}(6.333,8.3 \\
33,9.667)\end{array}$ & $\begin{array}{c}(3.667,5.66 \\
7,7.667)\end{array}$ & $\begin{array}{l}(5.667,7.6 \\
67,9.333)\end{array}$ & A30 & $\begin{array}{l}(3.667,5.6 \\
67,7.667)\end{array}$ & $\begin{array}{l}(4.333,6.3 \\
33,8.333)\end{array}$ & $(3,5,7)$ \\
\hline A11 & $\begin{array}{l}(4.333,6.3 \\
33,8.333)\end{array}$ & $\begin{array}{c}(5.667,7.66 \\
7,9.333)\end{array}$ & $\begin{array}{l}(3.667,5.6 \\
67,7.667)\end{array}$ & A31 & $\begin{array}{l}(0.333,1.6 \\
67,3.667)\end{array}$ & $\begin{array}{l}6.333,8.3 \\
33,9.667)\end{array}$ & $\begin{array}{l}(6.333,8.3 \\
33,9.667)\end{array}$ \\
\hline $\mathrm{A} 12$ & $\begin{array}{l}(5.667,7.6 \\
67,9.333)\end{array}$ & $\begin{array}{c}(1.667,3.66 \\
7,5.667)\end{array}$ & $(5,7,9)$ & A32 & $\begin{array}{l}(5.667,7.6 \\
67,9.333)\end{array}$ & $\begin{array}{l}(0.333,1.6 \\
67,3.667)\end{array}$ & $\begin{array}{l}(6.333,8.3 \\
33,9.667)\end{array}$ \\
\hline A13 & $\begin{array}{l}(5.667,7.6 \\
67,9.333)\end{array}$ & $\begin{array}{c}(1.667,3.66 \\
7,5.667)\end{array}$ & $(5,7,9)$ & A33 & $\begin{array}{l}6.333,8.3 \\
33,9.667)\end{array}$ & $(1.333,3,5)$ & $\begin{array}{l}(5.667,7.6 \\
67,9.333)\end{array}$ \\
\hline A14 & $\begin{array}{l}(3.667,5.6 \\
67,7.667)\end{array}$ & $\begin{array}{c}(2.333,4.33 \\
3,6.333)\end{array}$ & $\begin{array}{l}6.333,8.3 \\
33,9.667)\end{array}$ & A34 & $(5,7,8.667)$ & $(1.333,3,5)$ & $(5,7,8.667)$ \\
\hline A15 & $\begin{array}{l}(4.333,6.3 \\
33,8.333)\end{array}$ & $\begin{array}{c}(0.667,2.33 \\
3,4.333)\end{array}$ & $\begin{array}{c}(8.333,9.6 \\
67,10)\end{array}$ & A35 & $(5,7,8.667)$ & $(1.333,3,5)$ & $(5,7,8.667)$ \\
\hline A16 & $(5,7,8.667)$ & $\begin{array}{c}(1.667,3.66 \\
7,5.667)\end{array}$ & $\begin{array}{l}1.667,3.6 \\
67,5.667)\end{array}$ & A36 & $(3,5,7)$ & $(3,5,7)$ & $(5,7,8.667)$ \\
\hline A17 & $(5,7,8.667)$ & $(1.333,3,5)$ & $(5,7,8.667)$ & A37 & $(3,5,7)$ & $(1.333,3,5)$ & $(5,7,8.667)$ \\
\hline A18 & $\begin{array}{l}(4.333,6.3 \\
33,8.333)\end{array}$ & $\begin{array}{c}(3.667,5.66 \\
7,7.667)\end{array}$ & $\begin{array}{l}(5.667,7.6 \\
67,9.333)\end{array}$ & A38 & $\begin{array}{l}(3.667,5.6 \\
67,7.667)\end{array}$ & $(1.333,3,5)$ & $\begin{array}{l}(5.667,7.6 \\
67,9.333)\end{array}$ \\
\hline A19 & $\begin{array}{l}(5.667,7.6 \\
67,9.333)\end{array}$ & $\begin{array}{c}(2.333,4.33 \\
3,6.333)\end{array}$ & $\begin{array}{l}(5.667,7.6 \\
67,9.333)\end{array}$ & A39 & $\begin{array}{l}(5.667,7.6 \\
67,9.333)\end{array}$ & $\begin{array}{l}(1.667,3.6 \\
67,5.667)\end{array}$ & $\begin{array}{l}6.333,8.3 \\
33,9.667)\end{array}$ \\
\hline $\mathrm{A} 20$ & $\begin{array}{l}(4.333,6.3 \\
33,8.333)\end{array}$ & $\begin{array}{c}(0.333,1.66 \\
7,3.667)\end{array}$ & $\begin{array}{c}(7,8.667,9 . \\
667)\end{array}$ & $\mathrm{A} 40$ & $\begin{array}{l}6.333,8.3 \\
33,9.667)\end{array}$ & $\begin{array}{l}(0.333,1.6 \\
67,3.667)\end{array}$ & $\begin{array}{l}(3.667,5.6 \\
67,7.667)\end{array}$ \\
\hline $\begin{array}{l}\text { Criteria } \\
\text { weight }\end{array}$ & $(0.623)$ & $(0.153)$ & $(0.224)$ & $\begin{array}{l}\text { Criteria } \\
\text { weight }\end{array}$ & $(0.623)$ & $(0.153)$ & $(0.224)$ \\
\hline
\end{tabular}


Table 8: Final ranking of items in VIKOR

\begin{tabular}{|c|c|c|c|c|c|c|c|}
\hline Rank & Options & Rank & Options & Rank & Options & Rank & Options \\
\hline 1 & A5 & 11 & A12 & 21 & A27 & 31 & A16 \\
\hline 2 & A10 & 12 & A13 & 22 & A18 & 32 & A14 \\
\hline 3 & A1 & 13 & A28 & 23 & A26 & 33 & A24 \\
\hline 4 & A33 & 14 & A32 & 24 & A25 & 34 & A2 \\
\hline 5 & A22 & 15 & A9 & 25 & A6 & 35 & A38 \\
\hline 6 & A23 & 16 & A40 & 26 & A15 & 36 & A30 \\
\hline 7 & A19 & 17 & A21 & 27 & A11 & 37 & A36 \\
\hline 8 & A39 & 18 & A17 & 28 & A3 & 38 & A37 \\
\hline 9 & A7 & 19 & A34 & 29 & A & 39 & A29 \\
\hline 10 & A4 & 20 & A35 & 30 & A20 & 40 & A31 \\
\hline
\end{tabular}

The output results of 40 potential impairments of radiator Samand are classified in an ascending order (Table 10):

Table 9: The output results of risk priority of GAMS software with analysis technique

\begin{tabular}{|c|c|c|c|}
\hline Rank & Options & Rank & Options \\
\hline 1 & A10 & 11 & A6 \\
\hline 2 & A5 & 12 & A14 \\
\hline 3 & $\mathrm{~A} 1$ & 13 & A3 \\
\hline 4 & A4 & 14 & A12 \\
\hline 5 & A19 & 15 & A13 \\
\hline 6 & A39 & 16 & A15 \\
\hline 7 & A11 & 17 & A21 \\
\hline 8 & A18 & 18 & A9 \\
\hline 9 & A33 & 19 & A25 \\
\hline 10 & A7 & 20 & A27 \\
\hline
\end{tabular}

Table 10: Ascending ranking of data coverage analysis

\begin{tabular}{|c|c|c|c|}
\hline Rank & Options & Rank & Options \\
\hline 21 & A32 & 31 & A20 \\
\hline 22 & A28 & 32 & A23 \\
\hline 23 & A31 & 33 & A36 \\
\hline 24 & A22 & 34 & A38 \\
\hline 25 & A17 & 35 & A40 \\
\hline 26 & A26 & 36 & A29 \\
\hline 27 & A30 & 37 & A37 \\
\hline 28 & A34 & 38 & A24 \\
\hline 29 & A35 & 39 & A2 \\
\hline 30 & A8 & 40 & A16 \\
\hline
\end{tabular}

To have a better understanding, the total table is shown for ranking of all the three modes (Table 11).

Table 11: Total ranking of VIKOR, data coverage analysis and simple risk priority

\begin{tabular}{|c|c|c|c|c|c|c|c|}
\hline Rank & Simple RPN & VIKOR & DEA & Rank & Simple RPN & VIKOR & DEA \\
\hline 1 & $\mathrm{~A} 1$ & A5 & $\mathrm{A} 10$ & 21 & $\mathrm{~A} 21$ & A27 & A32 \\
\hline 2 & A13 & A10 & A5 & 22 & A22 & A18 & A28 \\
\hline 3 & A4 & A1 & $\mathrm{A} 1$ & 23 & A23 & A26 & A31 \\
\hline 4 & $\mathrm{~A} 2$ & A33 & A4 & 24 & A24 & A25 & A22 \\
\hline 5 & A5 & A22 & A19 & 25 & A25 & $\mathrm{A} 6$ & A17 \\
\hline 6 & A19 & A23 & A39 & 26 & A26 & A15 & A26 \\
\hline 7 & A20 & A19 & A11 & 27 & A27 & A11 & A30 \\
\hline 8 & A11 & A39 & A18 & 28 & A28 & A3 & A34 \\
\hline 9 & A15 & A7 & A33 & 29 & A29 & A8 & A35 \\
\hline 10 & A12 & A4 & A7 & 30 & A30 & A20 & A8 \\
\hline 11 & A3 & A12 & A6 & 31 & A31 & A16 & A20 \\
\hline 12 & A14 & $\mathrm{A} 13$ & A14 & 32 & A32 & A14 & A23 \\
\hline 13 & A16 & A28 & A3 & 33 & A33 & A24 & A36 \\
\hline 14 & A8 & A32 & A12 & 34 & A34 & A2 & A38 \\
\hline 15 & A18 & A9 & A13 & 35 & A35 & A38 & A40 \\
\hline 16 & $\mathrm{~A} 6$ & $\mathrm{~A} 40$ & A15 & 36 & A36 & A30 & A29 \\
\hline 17 & A9 & A21 & A21 & 37 & A37 & A36 & A37 \\
\hline 18 & A7 & A17 & A9 & 38 & A38 & A37 & A24 \\
\hline 19 & A10 & A34 & A25 & 39 & A39 & A29 & $\mathrm{A} 2$ \\
\hline 20 & A17 & A35 & A27 & 40 & $\mathrm{~A} 40$ & A31 & A16 \\
\hline
\end{tabular}

As we can see, in the simple risk priority of $2,3,4$, $5,6,7$, and other items have a same priority and the items of $4,13,1$ are the potential impairments and the items of 1,105 are the most important ones and the data coverage analysis suggests the $10,5,1$ items.

As the two methods have different nature, there are same priorities and it shows an equal decision making method in finding impairment priorities.

\section{Results analysis}

According to the analysis of potential impairments, the impairment modes with maximum risk priority are the most important ones, while this action differs in different methods. First the amount of risk priority for each impairment mode is phased with lingual words by experts. We here use phase theory to prevent real risk priority imperfections and as it was mentioned the analytical method and its effects are of equal value but different importance. So this study is a hierarchical method for each one of three factors of severity, occurrence and detection by Chang method calculation. 


\section{Discussion and conclusion}

In this study there is a new perspective on risk priorities by VIKOR, DEA, AHP. The phase perspective is used to weigh risk factors and impairment prioritizing. To do this, a compound model of VIKOR, DEA, FAHP is suggested and then this model is used in Iran Can Company. The results show that impairment of FM5, FM10, FM1 are the most important ones which are related to the low boil core diameter in the demolition test or nugget and hammer boil lines of P1, P6, joint of boil point in demolition test or nugget and hammer of PSW1, PSW2 and non-suitable facial conditions and incorrect montage.

For more research the results of this article can e compared with other multi-norms techniques of WASPAS, ELECTRE, PROMETHEE.

\section{References}

AlKhathlan K and Malik SA (2010). Are Saudi banks efficient? Evidence using data envelopment analysis (DEA). International Journal of Economics and Finance, 2(2): 53-58.

Amado CA, Santos SP and Marques PM (2012). Integrating the Data Envelopment Analysis and the Balanced Scorecard approaches for enhanced performance assessment. Omega, 40(3): 390-403.

Bowles JB and Peláez CE (1995). Fuzzy logic prioritization of failures in a system failure mode, effects and criticality analysis. Reliability Engineering and System Safety, 50(2): 203-213.

Braglia M (2000). MAFMA: multi-attribute failure mode analysis. International Journal of Quality and Reliability Management, 17(9): 1017-1033.

Braglia M, Frosolini M and Montanari R (2003). Fuzzy criticality assessment model for failure modes and effects analysis. International Journal of Quality and Reliability Management, 20(4): 503-524.

Chin KS, Chan A and Yang JB (2008). Development of a fuzzy FMEA based product design system. The International Journal of Advanced Manufacturing Technology, 36(7-8): 633-649.
Guimarães ACF and Lapa CMF (2007). Fuzzy inference to risk assessment on nuclear engineering systems. Applied Soft Computing, $7(1): 17-28$.

Lai $\mathrm{CH}$ and Wei MY (2007). A common weighted performance evaluation process by using data envelopment analysis models. In 2007 IEEE International Conference on Industrial Engineering and Engineering Management. IEEE: 827-831

Meng Tay K and Peng Lim C (2006). Fuzzy FMEA with a guided rules reduction system for prioritization of failures. International Journal of Quality and Reliability Management, 23(8): 10471066.

Pillay A and Wang J (2003). Modified failure mode and effects analysis using approximate reasoning. Reliability Engineering and System Safety, 79(1): 69-85.

Puri J and Yadav SP (2015). Intuitionistic fuzzy data envelopment analysis: an application to the banking sector in India. Expert Systems with Applications, 42(11): 4982-4998.

Sharma RK, Kumar D and Kumar P (2005). Systematic failure mode effect analysis (FMEA) using fuzzy linguistic modelling. International Journal of Quality and Reliability Management, 22(9): 986-1004.

Wang YM, Chin KS and Yang JB (2007). Measuring the performances of decision-making units using geometric average efficiency. Journal of the Operational Research Society, 58(7): 929-937.

Wang YM, Chin KS, Poon GKK and Yang JB (2009). Risk evaluation in failure mode and effects analysis using fuzzy weighted geometric mean. Expert Systems with Applications, 36(2): 11951207.

Xu K, Tang LC, Xie M, Ho SL and Zhu ML (2002). Fuzzy assessment of FMEA for engine systems. Reliability Engineering and System Safety, 75(1): 17-29. 